\title{
Maturation index assessment of sodium tripolyphosphate and tetra potassium pyrophosphate based calculus dissolution mouthrinse (periogen $®$ ) in moderate gingivitis patients: a histopathological study
}

\begin{abstract}
Background: Poor oral hygiene and colonization of dental plaque is likely to play an important role in periodontal disease progression that further alters systemic health. Mouthrinse are often used as adjunct with tooth brushing to supplement plaque control. The aim of this study was to evaluate the clinical efficacy of anti-calculus Mouthrinse in Maturity Index of oral epithelium of moderate gingivitis patients.
\end{abstract}

Materials and methods: Sixty subjects of moderate gingivitis were divided into three categories with twenty subjects in each group. Group A (Professional Prophylaxis followed by regular brushing and calculus dissolution based test mouthrinse), Group B: (Regular brushing and calculus dissolution based test Mouthrinse) and Group C: (Professional Prophylaxis followed by regular brushing only). The gingival epithelium smear was done two times for each subject, the first day prior to the use of mouthwash and on the 6th day after using mouthrinse for 5 consecutive days.

Results: The subjects under group A (Professional prophylaxis and Test mouthrinse) showed $19.11 \%$ turn overrate followed by group B (Test mouthrinse only) with $14.08 \%$ and last with Group C (Professional prophylaxis) with only $6.49 \%$.

Conclusion: The test mouthrinse in this study significantly proved to switch the Maturation Index and this Mouthrinse will promote wound healing.

Keywords: maturity index, wound healing, gingivitis
Volume 6 Issue 6 - 2017

\author{
Regina TC Tandelilin,' Alma Linggar Jonarta,' \\ Elastria Widita ${ }^{2}$ \\ 'Department of Oral Biology, Universitas Gadjah Mada, \\ Indonesia \\ ${ }^{2}$ Faculty of Dentistry, Universitas Gadjah Mada, Indonesia
}

Correspondence: Regina TC Tandelilin, Department of Oral Biology, Faculty of Dentistry, Universitas Gadjah Mada, Yogyakarta, Indonesia, Email oralbioscience@gmail.com

Received: January 19, 2016 | Published: March 30, 2017

\section{Introduction}

Periodontal tissues symbolize a distinctive organization in the oral cavity where epithelial, soft and mineralized connective tissues come together to form a complex junction, referred to as the dent gingival junction. Gingiva is the part of oral mucosa that covers the alveolar process of jaw and surrounds the neck of teeth. Gingiva is divided anatomically into three parts Marginal, Attached and Inter dental papilla as illustrated in Figure 1. Gingival epithelium consists of three regions: oral gingival epithelium (OGE), sulcular epithelium (SE) and junctional epithelium (JE). JE is a specialized gingival epithelium locating at the junction of periodontal soft tissue and hard tissue, and attaching to the crown or root like a collar. ${ }^{1}$ Layered epithelium of the gingiva consists of four layers the Stratum basale, Stratum spinosum, Stratum granulosum and Stratum corneum. The basal layer is where the process of proliferation of cells differentiated into layers above it causing epithelial maturation. Differentiation involves the process of keratinization i.e. biochemistry and morphological changes that occur in cells along with migration from the basal layer to corneum layer. Oral mucosa undergo a process of cell turnover and exfoliated cell is an instrumental in helping the diagnosis of local and systemic disease which can be seen from both the nucleus and the cell morphological variations. ${ }^{2}$ The rate of mitosis is higher in non-keratinized areas which increases when there is inflammation of the gingival. ${ }^{3}$ Changes in the epithelial layer of histological some of them saw is the release of superficial cells and increased basal cell proliferation are rapidly. ${ }^{4,5}$ Periodontal diseases are recognized as infectious processes that require bacterial presence and a host response and are further affected and modified by other local, environmental, and genetic factors. ${ }^{6}$ Periodontitis is initiated by oral biofilm formation if untreated progress to gingivitis further leading to periodontal disease. The link between periodontal disease and systemic diseases has been scientifically proven over last two decades. The principle reason for this oral- systemic connection is dissemination of locally produced proinflammatory mediators such as $\mathrm{C}$ - reactive protein, interleukins-1 beta (IL-1 $\beta$ ) and IL-6 and tumor necrosis factor alpha.

Gingivitis is a disease of the oral cavity with high prevalence rate initiated by dental plaque accumulation. Initial sign of gingivitis are bleeding gums, inflammation and halitosis. Gingivitis is the initial 
stage of disease progression and can further extend to periodontitis if the bacterial bio burden is not eradicated by the optimal means. Gingivitis causes changes in epithelial maturation rate that lead to increase activity of basal cell proliferation and reduced superficial cell. With the reducing of gingival inflammation therefore it will be increased the number of keratinized superficial cells which has function as epithelium protective layer. The turnover rate of this kind of epithelial is 6-10 days. ${ }^{3-7}$

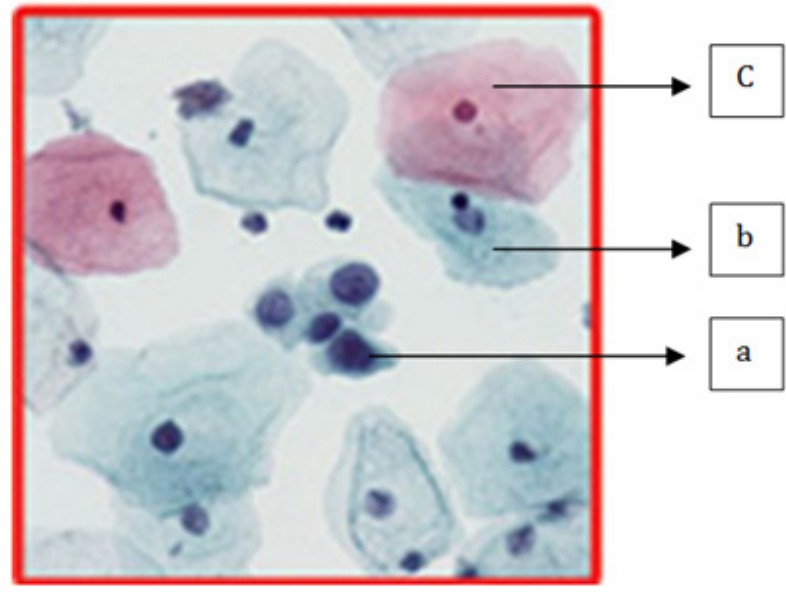

Figure I Epithelial cells.

a. Basal cells with round and large nucleus,

b. Sel intermediate cells with round to oval shape nucleus,

c. Superficial cells with piknotic nucleus. ${ }^{8}$

There are many methods to treat gingivitis, one of this method could be supplementing toothbrush by using mouthrinse. The majorities of the Mouthrinse contain alcohol which reduces the accumulation of dental plaque by denaturating the bacterial cell, breakdown the enzyme in the plaque matrix and inhabitation of bacterial aggregation or inhibit the attachment of bacteria to the tooth surface. There is lot of disadvantages for prolonging the use of alcohol based Mouthrinse and hence more tissue friendly Mouthrinse need to be explored for their clinical efficacy and adjunct benefits. The main aim of this study was to examine the cell maturity index after 5 days of consecutive Mouthrinse with sodium tripolyphosphate and tetrapotassium pyrophosphate based calculus dissolution Mouthrinse (Periogen $($ ) in moderate gingivitis patients and to evaluate whether it could accelerate the oral mucosal wound healing.

\section{Materials and methods}

\section{Research subjects}

Sixty subjects with moderate gingivitis were chosen based on determined inclusion criteria as listed in Table 1. The research subjects were recruited by random sampling and subjects were divided into three groups, twenty subjects per group. The treatment of each group is summarized in Table $1 \& 2$. Ethical clearance has been granted by Research Ethic Commission of the Faculty of Dentistry, Universitas Gadjah Mada, and Indonesia. Informed consent was signed after subjects were explained with protocol of this research. The only subjects under Group A and C went under professional prophylaxis under similar clinical settings.
Table I Inclusion criteria

Mild gingivitis patients

Age : 17-55 years old

Do not have past or recent chronic systemic diseases

Do not recently take medications affecting inflammatory status of gingiva, such as : cholinergic, anticholinergic, antibiotic, antiinflammatory drugs

Do not wear any type of prosthetic or orthodontic devices

Does not undergone professional prophylaxis last six months

Subjects should have a minimum of 20 sound permanent teeth with minimum of 5 teeth to be present in each arch quadrant

Pregnant and Lactating women

Table 2 Group treatment

\begin{tabular}{lllll}
\hline \multirow{5}{*}{ Group } & \multicolumn{2}{l}{ Treatment protocol } \\
\cline { 2 - 5 } & $\begin{array}{l}\text { Professional } \\
\text { scaling }\end{array}$ & $\begin{array}{l}\text { Tooth } \\
\text { brushing }\end{array}$ & flossing & $\begin{array}{l}\text { Periogen } \\
\text { mouthrinse }\end{array}$ \\
\hline A $(n=20)$ & Yes & Yes & Yes & Yes \\
B $(n=20)$ & No & Yes & Yes & Yes \\
C $(n=20)$ & Yes & Yes & Yes & No
\end{tabular}

Sixty research subjects divided into three categories (Group A to $\mathrm{C}$ ) were instructed to do mouthrinse 2 times a day after brushing (Morning and Night) for 5 consecutive days. In this study we use Periogen (The Periogen Company, USA) as a mouthwash which contains of tetrapotassium Pyrophosphate, Sodium Tripolyphosphate, Sodium Bicarbonate, Citric-acid and Sodium Fluoride 0.04\%. Subjects were advised to dissolve 1 spoon full of Periogen powder in $100 \mathrm{ml}$ of warm water. Swish solution in mouth for at least 1 minute in three 20-second intervals essentially using all the mixture. Cups with standardized volume quantity of $100 \mathrm{ml}$ were also provided to each subject/participant for their compliance. The research subjects were instructed not to eat or drink for 30 minutes after using mouthwash.

\section{Histopathology test}

The gingival epithelium smear was done 2 times for each subject, the first day prior to the use of Periogen mouthwash and on the 6th day after using Mouthrinse for 5 consecutive days. Cytobrush was rotated on the attached gingival epithelium which had the highest score on gingival inflammation. Cells attached on cytobrush were then immediately smears on a glass object then fixed in $96 \%$ alcohol then followed by histological process staining using Papaniucolaou.

\section{Maturity index}

Changes in the maturation process of the gingival epithelium can be observed using exfoliate cytology using the Papanicolaou stain. Examinations of the slide were done using a light microscope with a magnification power of 400x. A hundred of non-overlapping random cells in some field of view were exanimate. The maturation index (MI) described the relative proportion of parabasal, intermediate and superficial cells in gingival cytology. The maturation index $=$ P: I: S where; 
a. $\quad \mathrm{P}=$ Percent Basal-Para basal cells

b. I=Percent Intermediate cells

c. $\mathrm{S}=$ Percent Superficial cells

Slide examination: Figure 1

1. Basal cells: parabasalcells, blue or dark blue cells, cuboidshaped, round and large shape nucleus.

2. Nucleus: cytoplasm ratio is $8: 10$, while the ratio of nucleus: cytoplasm of cells parabasal 5:10.

3. Intermediate cells: blue or pink cells, polygonal shaped, oval or round, round to oval shape nucleus, smaller than the size of basal - parabasal cell nucleus. Ratio of nucleus: cytoplasm's 2:10.

4. Superficial cells: red cells, polygonal shaped but sometimes round or oval, piknotic (small and dark) nucleus.

5. Ratio of nucleus: cytoplasm is $1: 10$.

6. The basal cell layers (the reserve cell layer): this layer consists of one row of cells. These are very small cuboidal cells with relatively large nuclei. They are firmly attached to basement membrane and not exfoliated.

7. The para basal cell layer: this layer is composed of several rows of cells. They are slightly larger with central nuclei also slightly larger. Para basal cells exfoliate. The exfoliated parabasal cells are squamous, small, round or oval. They stain blue against a clear and clean background while Cytoplasm is compact and central nuclei relatively large.

8. The intermediate cell layer: composed of several rows of cells These are flatter in shape. Nuclei are vesicular. Superficial cells are a dark eosinophilic color with pyknotic nuclei. Groups of 3 or more cells should not be counted and at least 100 cells should be counted.

The Maturation Value is $=1.0 \mathrm{x}$ (percent superficial cells $)+0.5 \mathrm{x}$ (percent intermediate cells) + (percent parabasal cells).

\section{Result and discussion}

In this research study design we examined the cell maturity after 5 executive days of serial Mouthrinse with Periogen. The results in maturation index are illustrated in Table 3. The aim of this study was also to evaluate the difference of the capacity of the Periogen mouthwash toward the epithelium maturity before the full maturity will be occurred on the lowest (basal) layer. This will be the important thing to evaluate the Periogen mouthwash material could accelerate the oral (mucosal) wound healing toward optimal oral health.

Table 3 Gingival epithelial maturation index

\begin{tabular}{lll}
\hline Group & Before & After \\
\hline A & $0: 32: 68$ & $0: 19: 81$ \\
B & $0: 29: 71$ & $0: 19: 81$ \\
C & $0: 23: 77$ & $0: 18: 82$
\end{tabular}

This study indicate that group A and B using Periogen mouthrinse showed more significant results with regard to changes of maturation index and maturation value that shifted after Mouthrinse which is marked by increase number of superficial cell $(19.11 \%$ and $14.08 \%)$. The subjects under group $\mathrm{C}$ without using Periogen mouthrinse showed with only $6.49 \%$ shifting of maturation index. Shifted maturation index indicates that epithelial cells of gingiva experience an increase of maturation to the direction of normal condition, which is different with the previous maturation index before gargling that showed accumulation of intermediate cell. The transformation of maturity index is due to gingivitis i.e. a response of non-specific inflammation caused by dental plaque. ${ }^{9}$ In the previous study by Squier et al. ${ }^{10}$ stated that bacterial irritation on gingiva could blocked the epithelial gingiva cell differentiation. ${ }^{10}$ Cells on basal layer will response with an increase of proliferation ability in the inflammation state. $^{11,12}$

Superficial cells that increased after Mouthrinse in group B even without professional scaling showed that Periogen material has the potential to decrease the inflammation indirectly by decreasing or suppressing the cause of local irritation of gingiva. In the other hand group $\mathrm{C}$ where scaling was done without using Mouthrinse indicates maturation index also shifted to the right and number of superficial epithelial cell showed no significant differences compare to group A nor group B. Phagocyte in inflammation condition can induce the production of free radical oxygen. ${ }^{13}$ Increased of free radical oxygen induced the formation of oxidative pressure that could worsen the inflammation condition with the present of excessive leukocyte infiltration. Free radical formation is controlled naturally by various beneficial compounds known as antioxidants. ${ }^{14}$ Periogenkey ingredients include Sodium Tripolyphosphate, Tetrapotassium Pyrophosphate, Sodium Bicarbonate, Citric Acid and Sodium Fluoride $(.04 \%)$. Citric acid apart of being used as an astringed further has an anti-oxidant property which could increase the proliferation cell on basal layer that is followed by increased of death cell which function to minimize the number of living defected cell and bacterial invasion to deeper tissues. This action of citric acid in $\mathrm{pH}$ balanced patented formulation will add the anti-oxidant property in the Mouthrinse (Periogen) that accelerates cellular health in the oral cavity. The six month clinical study also proved that Periogen is an important tool for formation and eradication of dental calculus as the Tetrapotassium pyrophosphate and sodium tripolyphosphate result in reduced calcification of dental plaque. ${ }^{15}$ Periogen mouthwash ingredients that contain citric acid act as anti-oxidants can increase cell proliferation in the basal cells layer, followed by an increase in cell death serves to limit the number of defected living cells and bacterial invasion into deeper tissues. ${ }^{12}$ Turn over gingival epithelial cells can lead towards normal by reducing the number of bacteria irritant so it can balance the process of cell division and release superficial basal cell. ${ }^{10}$

The average and standard deviation of basal-parabasal cells, intermediate cells and superficial cells of moderate gingivitis patients was summarized in Table 4. The value of Test of Normality and Homogeneity of Variances on Day 0 was summarized in Table 5 shows assumed that all the subjects were normal and homogenized. Clinically in all groups have an increasing number of superficial cells Table 3. After 5 days mouthrinse the result appears Gingival Index decreased Table 4 indicating that gingiva went through wound healing process. This is in accordance with Garrantet et al. ${ }^{12}$ which states that the healing period increased epithelial cell renewal rate. Increased proliferation of cells can occur due to the increasing number of dividing cells in the basal layer, shortening of the period of the cell cycle, or increasing the number of cells undergoing maturation 
division. The severity of gingival inflammation is determined by the balance of pro-inflammatory cytokines and anti-inflammatory numbers. ${ }^{16,17}$ Epithelial proliferation in gingivitis was induced by the presence of inflammatory cytokines, such as TGF $\alpha$, TGF $\beta$, KGF, EGF, IL1 $\alpha$, IL-1 $\beta$, IL-6 and IL-8. Inflammatory cytokines plays a role in increasing the activity of basal cell division, thus accelerating the maturation process of the inflamed gingival epithelium. ${ }^{18-20}$ In this study, after 5 days, the results indicate that maturation index has been shifted to right Table 3, this is in accordance with the Wolf et al. ${ }^{7}$ which states that the replacement process of the gingival epithelium within the range of 6-10 days. In a study by Davis et al stated that inflammation can trigger an increased release of superficial cells resulting in increased mitosis in the basal cells to replace cells that are loose..$^{21}$ With the loss factor of the inflammatory irritant it will not peel off excess of superficial cells. This cause the cells in the lower layers would quickly move to the outer layers without excessive of superficial cell death that is histological not found the basal-parabasal cells. Result of Gingival Index ANOVA using Kruskal Wallis et al. on day 5 th has 0.005 showed significantly difference that Periogen has effect in gingival inflammation within all groups of the samples and proved that it was worked to reduce the gingival inflammation (Table 6) which is summarized the significantly comparison between groups. It shows that Periogen have the same effectiveness by scaling action in lowering the GI score. Willet et al. ${ }^{22}$ states that gingivitis can be increased with the increasing accumulation of bacterial plaque. Thus Periogen role as anti plaque by preventing the attachment of bacteria that causes plaque accumulation and gingivitis.

Table 4 Mean and standard deviation values of gingival index based on day

\begin{tabular}{lll}
\hline \multirow{2}{*}{ Group } & Day 0 & Day 5 \\
\cline { 2 - 3 } & \pm SD & \pm SD \\
\hline A & $1.44 \pm 0.25$ & $0.73 \pm 0.27$ \\
B & $1.26 \pm 0.11$ & $0.84 \pm 0.21$ \\
C & $1.37 \pm 0.18$ & $0.89 \pm 0.13$
\end{tabular}

Table $\mathbf{5}$ Test of normality and homogeneity of variances on day 0

\begin{tabular}{lll}
\hline \multirow{3}{*}{ Group } & \multicolumn{2}{l}{ Gingival index } \\
\cline { 2 - 3 } & \multicolumn{2}{c}{ Test of normality $\begin{array}{l}\text { Test of homogeneity of } \\
\text { variances }\end{array}$} \\
\cline { 2 - 3 } & Sig. & Sig. \\
\hline A & 0.2 & 0.064 \\
B & 0.064 & \\
C & 0.2 & \\
\hline
\end{tabular}

Table 6 Mann whitney test for gingival index in between group $(p<0.05)$

\begin{tabular}{llll}
\hline \multirow{2}{*}{$\begin{array}{l}\text { Time after } \\
\text { Gargling }\end{array}$} & Group A-Group B Group A-Group CGroup B-Group C \\
\cline { 2 - 4 } & Sig. & Sig. & Sig. \\
\hline Day 5 & $0.010^{* *}$ & $0.003^{* *}$ & 0.524
\end{tabular}

\section{Conclusion}

This study confirmed that consistent use of Periogen mouthrinse play a significant in plaque control to accelerate in gingival wound healing by increasing turnover of superficial cell number. There is no adverse effect reported among any of subject using Periogen mouthrinse.

\section{Acknowledgments}

We would like to thank Dr. Heriati Sitosari, Benni Prayuda $\mathrm{BScDH}$ and Dr. Finsa Tisna Sari, for supporting this research as blind reviewers in counting the cells and helping the research preparation.

\section{Conflicts of interest}

The authors declare there is no conflict of interest.

\section{References}

1. Jiang Q, Yu Y, Ruan $\mathrm{H}$, et al. Morphological and functional characteristics of human gingival junctional epithelium. BMC Oral Health. 2014;14:30.

2. Perez Sayans M, Somoza Martin JM, Barros Angueira F, et al. Exfoliative Cytology for diagnosing oral cancer. Biotech Histhochem. 2010;85(3):177-187.

3. Newman MG, Takei H, Klokevold PR, et al. Caranza's Clinical Periodontology: A South Asian. 11th ed. New Delhi, India: Elsevier; 2013:1-1500.

4. Kazuyoshi O. A study of Exfoliative cytology in periodontal disease the Relation Between a degree of inflammmation, Cytological Findings and Histopathological Findings. JSP. 2005;18(2):189-206.

5. Mysorekar IU, Isaacson-Schimid M, Walker JN, et al. Bone morphogeneticprotein 4 signaling Regulates Epithelial Renewal in the Urinary Tract in Response to Urphathogenic Infection. CHMJ. 2009;5(5):463-475.

6. Saini R, Saini S, Saini SR. Periodontitis: A risk for delivery of premature labor and low birth weight infants. J Nat Sci Biol Med. 2011;2(1):50-52.

7. Wolf HF, Rateitschack EM, Rateitschack KH, et al. Color Atlas of Dental Medicine. 3rd ed. New York, UK: Thieme; 2006:1-20.

8. Afriadi LN. The influence of Clover flower essential oil (Syzygium aromaticum. (L.)) solutin as mmouthrinse toward the index maturation of gingivital ephithelium of moderate gingivitis patients. Undergarduate Thesis of Faculty of Dentistry, Universitas Gadjah Mada 39. 2010.

9. Bartold PM, Narayanan AS. Molecular and Cell Biology of Healthy and Diseased Periodontal Tissues. J Periodontol. 2006;40:29-49.

10. Squier C. Keratinization of the Sulcular Epithelium- A Pointlesss Pursuit? J Periodontol. 1981;52(8):426-429.

11. Carro OM, Evans SA, Leone CW. Effect of Inflammation of the Proliferation on Human Giniva Epithelial Cells in Vitro. J Periodontol. 1997;68(11):1070-1075.

12. Garrant PR. Oral cells and Tissue. Canada: Quintessence Publishing; 2003:1-400.

13. Quintanilha A. Reactive Oxygen Species in Chemistry, Biology and Medicine. London, UK: Plenum Press; 1988:1-160.

14. Mittal M, Siddiqui MR, Tran K, et al. Reactive Oxygen Species in Inflammation and Tissue Injury. Antioxid Redox Signal. 2014;20(7):11261127.

Citation: Tandelilin RTC, Jonarta AL,Widita E. Maturation index assessment of sodium tripolyphosphate and tetra potassium pyrophosphate based calculus dissolution mouthrinse (periogen $®$ ) in moderate gingivitis patients: a histopathological study.J Dent Health Oral Disord Ther. 2017;6(6):I66-I70. DOI: 10.15406/jdhodt.2017.06.002 I8 
15. Saini R, Saini S, Sharma S. Antioxidants accelerates cellular health. Int J Green Pharm. 2010;3:212.

16. Saini R. A Prospective Experimental Comparative Study on the Clinical Effects of Calculus Dissolution based Oral Rinse in Gingivitis Patients. Int J Experiment Dent Sci. 2015;4(1):33-39.

17. Bansal J, Bansal A, Shahi M, et al. Periodontal Emotional Stress Syndrome. Review of Basic Concepts, Mechanism and Management. OJMP. 2014;3:250-261.

18. Nanci A. Ten Cate's Oral Histology. 8th ed. St Louis, Missouri, USA 2008:1-284
19. Bryant R, Nix DP. Acute and Chronic Wounds: Current Management Concepts. St Louis, Missouri, USA: Elsevier; 2016:66.

20. Tawfig N. Proinflamatorry Cytokines and Periodontal Disease. J Dent Probl Solut. 2016;3(1):12-17.

21. Davis WC. Oral Histology Cell Structure and Function. Philadelphia, USA: WB Saunders Company; 1986:1-230.

22. Willet NP, White RR, Rosen S. Essential Dental Microbiology. USA: Prentice Hall; 1991:373. 